\title{
Buildings environmental impacts' sensitivity related to LCA modelling choices of construction materials
}

Ian-Frederic Häfliger ${ }^{1}$, Viola John ${ }^{1}$, Alexander Passer ${ }^{2}$, Sebastien Lasvaux ${ }^{3}$, Endrit Hoxha ${ }^{4}$, Marcella Ruschi Mendes Saade ${ }^{2,5}$, Guillaume Habert ${ }^{1^{*}}$

${ }^{1}$ Institute of Construction and Infrastructure Management, Chair of Sustainable construction, Swiss Federal Institute of Technology (ETH Zurich), Stefano Franscini Platz 5, 8093 Zürich, Switzerland

2 Institute of Technology and Testing of Building Materials, Graz University of Technology, Inffeldgasse 24, 8010 Graz, Austria

${ }^{3}$ University of Applied Sciences of Western Switzerland (HES-SO), School of Business and Engineering Vaud (HEIG-VD), Laboratory of Solar Energetics andBuilding Physics (LESBAT), Switzerland

${ }^{4}$ Ecole Polytechnique Fédérale de Lausanne (EPFL), Building 2050 Research Group, Fribourg, Switzerland

${ }^{5}$ Dept of Civil engineering, architecture and urbanism, State university of Campinas (UNICAMP), Campinas, SP, Brazil

*Corresponding author: Guillaume Habert, habertg@ethz.ch

\begin{abstract}
The assessment of the environmental performance of buildings is now commonly using a life cycle approach, based on a growing number of databases and methods in Life Cycle Assessment (LCA). Recent studies have however highlighted the problems related to uncertainties in the LCA results. The aim of this study is to assess the sensitivity of construction materials to the different modelling choices in order to highlight their consequences at the building scale. In particular we focused on the different modelling options in terms of database choices, system boundaries definitions and replacement scenarios of building materials during the whole service life of the buildings. The assessment of uncertainties was conducted at two levels: the material or element level and the building level. The results clearly show the importance of these modelling choices. Variations on the overall assessment of buildings are significant, but the details at the material scale show that not all materials perform similarly to these choices. We identified those materials that have a large contribution to the environmental impact of the buildings and which are also sensitive to different modelling choices. This can help for a better understanding of these modelling choices that can be used in upcoming regulations or public policies.
\end{abstract}


Keywords: Environmental Product Declaration; Uncertainty; Module D; System Boundary; LCA

\section{Introduction}

By the end of the 20th century, the sustainable development concept was introduced, paving the way for sustainability assessment approaches in the construction sector. The construction sector accounting for one third of the overall greenhouse gas emissions (UNSTAT, 2010) is a crucial point in global Sustainable development. In the past, the development of sustainability for buildings mainly focused on the energy demand and emissions during the building use phase. But, since the emergence of low energy building, studies showed the importance of embodied energy and emissions during building constructions (Sartori and Hestnes, 2007). Life Cycle Assessment (LCA) has then been established as the appropriate method to grasp the overall environmental impact of buildings (Blengini and Di Carlo, 2010a).

The method is however not fully secured and many studies highlight the methodology's comparability and consistency issues. Huijbregts (1998) defines those issues as uncertainties due to choices. In particular, they are concerned with uncertainties related to the functional unit and system boundaries definition, the databases used or the End-of-Life (EoL) modelling (Lloyd and Ries, 2007). Harmonization procedures such as ISO 14040 for LCA (ISO, 2006) or specific standards for building products such as the EN 15804 or the ISO 13315 (ISO, 2014), unfortunately do not allow to avoid uncertainty in modelling choices, even if they manage to limit them. Various methods are proposed to quantify these uncertainties: scenario analysis, quantitative uncertainty analysis and sensitivity analysis. For example, Hoxha et al. (2014) propose an analytical approach for uncertainties quantification due to construction material service life sensitivity. Huijbregts (1998) used a probabilistic modelling for assessing the effect of different allocation procedures and different time horizons for global warming potential. Aktas and Bilec (2012) estimate the uncertainties due to service life on US residential buildings, based on a Monte Carlo Simulation. These studies show a non-negligible effect of the modelling choices on the analysed buildings LCA results.

Most of the existing studies assess uncertainties due to some of the modelling parameters, but mainly at the building level (whole building LCA), or they assess them at the material scale and focus only on one parameter, such as data quality (Wang et al., 2012), system boundaries aspect (Silvestre et al., 2014) or building materials service life (Noshadravan et al., 2013). The aim of this study is to assess, both at building and construction materials levels, the sensitivity to different modelling choice uncertainties in order to assess each uncertainty parameter's relative contribution to the overall material variance, and the relative importance that each material has on the environmental 
assessment's overall result. For this purpose, four buildings were selected and a sensitivity analysis was conducted with regard to the choice of inventory databases, system boundary definition, replacement scenarios and building reference study period (RSP).

\section{Material and Methods}

As defined by Blengini and Di Carlo (2010b), there are two main levels of details in construction and buildings LCA. Firstly, the comprehensive building LCA analyzes all the environmental impacts of a building over its entire life span; and secondly, construction material LCA assesses or compares materials' environmental impacts. In this study, both levels of detail are covered. The sensitivity of four modelling choices, namely functional unit, system boundaries, replacement scenario and foreground databases, are evaluated at the building and material scale. Results are structured to first present the material contribution to the buildings' environmental performance, followed by the overall variability in terms of modeling choices.

Heijungs (1996) introduced the notion of identifying key issues for improving LCA's reliability, according to their uncertainty and contribution to the final output. In our study, analogously to Heijungs's sensitive data categorization system, a building material is classified as sensitive when its contribution and the variability of a parameter are above a certain threshold. Based on the authors' experience and knowledge, we have chosen to consider that if a building material contributes more than $10 \%$ to the total building's impact, this material is assumed to have a significant contribution. Similarly, if a material's results vary more than $20 \%$, it is assumed to have a significant variability. The latter threshold is in line with Hong et al. (2016) findings, which showed that a coefficient variation of $18 \%$ in uncertainty analysis can be considered as a baseline for establishing critical input parameters.

\subsection{Chosen buildings and associated construction materials}

The four buildings under study in this paper are newly built multi-family houses. All buildings have been recently built (after 2010) in Switzerland and present advanced energy performances. The buildings diverge in terms of size, number of floors, construction types and building materials. The data collection process and the buildings' full description is available in the Doctoral thesis of V. John (John, 2012) but table 1 summarizes the buildings main characteristics and figure 1 shows main materials relative proportion. We considered two massive buildings made with concrete, one medium weight building made with a mix of wood and concrete as structural materials and one lightweight building with a wooden structure.

\subsection{Modelling choices}

\subsubsection{Databases and datasets}


LCA is a data-intensive method, which requires adequate and reliable data to model processes' environmental impacts (Peereboom et al., 2008). For the building sector, Takano et al. (2014) analyzed five $\mathrm{LCl}$ databases on three "box buildings". The outcomes indicated that for these five generic databases the results were of the same magnitude and showed similar trends, however they revealed "quite large" numerical variations.

Anand and Amor (2017) state that buildings inventory data can come from three sources: the building industry, databases or Environmental Product Declarations (EPDs). For this study, following the previous categorization, we adopted three different databases/datasets for the four buildings' environmental impacts evaluation: Ecoinvent v2.2 database (Frichknecht and Jungbluth, 2007), Swiss Catalogue Construction/KВOB datasets (KBOB, 2009) and Environmental Product Declarations (EPD) (IBU, 2016). The latter consists of product-oriented specific data, while the two others contain average datasets. A short presentation of the databases /datasets is given below. The provided supplementary material lists each product EPD used, and materials' names in Ecoinvent v2.2 and KBOB, to allow for reproducibility. Whenever more than one EPD was available for the same product, authors calculated the average value between them to be used in this assessment.

\section{Ecoinvent v2.2}

The Ecoinvent database is a $\mathrm{LCl}$ database developed by the Ecoinvent Centre, which is a competence centre of the Swiss Federal Institutes (e.g. the Swiss federal Institute of Technology of Zurich and Lausanne and EAWAG, PSI etc.). Since the year 2000, three versions of the database have been published. For the purpose of this study the version 2.2 was utilized. This database is one of the most widely used databases in Europe and covers over 4000 processes, including over 120 different building materials (Frichknecht and Jungbluth, 2007).

\section{KBOB Datasets}

KBOB Datasets are a project undertaken by the Swiss Authorities for sustainable construction (KBOB, 2009). The datasets are associated with an LCA software named Bauteilkatalog, which is a praxisoriented online planning tool utilized for construction projects comparison at early design stages. It is being used in various national standards, certification schemes and technical bulletins in Switzerland Frischknecht (Frichknecht et al., 2015). The KBOB datasets rely on Ecoinvent v2.2 process information as background data.

EPDs

Environmental Product Declarations (EPD) are "verified documents that report environmental data of products based on Life Cycle Assessment [...] in accordance with the international standard ISO 14025 (ISO, 2006)". EPDs will be essential for the assessment of buildings' environmental performance in the near future (Passer et al., 2015). The EPDs utilized in this study were selected by the German EPD supplier, the Institute für Bauen und Umwelt (IBU) (IBU, 2016) except for one EPD 
(plastic fleece) which was semlected from another supplier (environdec, 2016). Their EPD program holds more than 700 declarations for building products. Until this research was finalized, to the authors' knowledge, no Swiss EPD program had been put in place. That fact, along with IBU's relevance and focus on the built environment, justified adoption of the German institute's declarations. The application of these EPDs as datasets was used in accordance with the European Standards EN 15804 and EN 15978 (EN, 2011; EN, 2012).

The rationale for choosing these three databases is that they have a common geographic representativeness as well as a common time frame for the data collection. The detailed names of all processes used in the calculation are gathered in Supplementary materials.

\subsubsection{System boundary and End-of-Life approaches}

Due to the comparative nature of LCA studies, a clear definition of system boundaries is required. (Tillman et al., 1993). Indeed, the selection of an inappropriate system boundary may result in incorrect modelling of the reality which can lead to incorrect interpretation of results and inappropriate comparison of studies (Reap et al., 2008). EN 15978 proposes three different life cycle models for the building's system boundary within LCA, known as Cradle-to-Gate, Cradle-to-Grave, and Cradle-to-Cradle approaches (Silvestre et al., 2014). The first life cycle model, Cradle-to-Gate, takes into account all environmental impacts from construction materials production until their arrival at the construction site. The second life cycle model, Cradle-to-Grave, adds the building's use phase and the EoL impacts to the Cradle-to-Gate scenario. And the third life cycle model, Cradle-toCradle, is achieved through a Cradle-to Grave scenario plus the potential benefits of reuse and recycling (Braungart et al., 2007), which refer to the module D - Reuse recovery and/or recycling potentials proposed by the European standard EN 15804 (EN, 2012).

Furthermore, Cradle-to-Grave and Cradle-to-Cradle system boundaries are modelled with different EoL approaches. Roughly, two methodologies are present in the literature for materials EoL modelling: the "recycled content approach" (or cut off approach) and the "end-of-life recycling approach" (or avoided burden approach) (Frichknecht, 2010). The Cradle-to-Grave system boundaries are based on the first approach while the Cradle-to-Cradle approach is based on the second one. Both approaches are compliant with the ISO standards and are also promoted by the European standards. However, modelling construction EoL with the two different approaches may strongly affect the results (Sandin, 2014). Gomes et al. (2013) recommend conducting a sensitivity analysis whenever alternative EoL modelling is applicable.

In this study, the EPDs standardized modular structure are used in order to model three different life cycle models and system boundaries for the four buildings' assessment. Cradle to gate, cradle to grave and cradle to cradle analysis are performed (Figure 2). Concerning the end of life hypothesis, 
including or disregarding Module D allows to consider the two main approaches mentioned in literature (avoided burden and cut-off approaches) (Frichknecht, 2010).

\subsubsection{Replacement scenarios and material service life}

The replacement phase impact is a function of the building Reference Study Period (RSP) and the Reference Service Life (RSL) of the different construction materials. In the case of discrete Material Service Life (MSL) values, the number of replacements $\left(n_{i}\right)$ is evaluated with eq. 1 :

$n_{i}=\frac{R S P}{M S L}-1$

For the MSL value determination, the Scientific and Technical Centre for Building (CSTB) database was used. It comes from a large literature review that gathers variability of service life for the different building materials and provides for each material an average service life and a standard deviation. A sample is available in Hoxha et al. (2014). Based on a Monte Carlo simulation $(30,000$ iterations) and eq. 2, uncertainties for the replacement phase were calculated.

$\sum_{i=1}^{n+1} M S L_{i} \geq R S P \quad$ where $M S L_{1} \neq \cdots \neq M S L_{n+1}$

The input data for the construction material service lives were modelled as normal distributed service lives and the outcome of the simulation was then fitted with the software @risk (Murtha, 2000). The uncertainty analysis was based on the geometric mean and standard deviation. The simulation was run independently for every material or composite element (elements composed of several construction materials with identical service lives), and then assembled at the building scale by the central theorem law.

\subsubsection{Functional unit}

In building LCA, the functional unit (FU) has to be defined in a way that allows for comparison of the different buildings' environmental impacts. The compared buildings have to provide a similar function (e.g. similar life span and similar services). The FU in this study is defined as $1 \mathrm{~m}^{2}$ of energy reference area per year; all four buildings have been newly built as of 2010 and comply with the state of the art and functional requirements of Swiss building regulations; the impacts are normalized by the building's size (energy reference area) and life span (years).

In Switzerland for building LCA, the reference study period is chosen at 60 years (SIA, 2010). For this study's purpose, the building RSP was also doubled to 120 years in order to assess the sensitivity of this parameter on the results. A report recently published by the International Energy Agency's (IEA) Annex 57 showed a great variability when service lives of 100 and 150 years were considered in comparison to 50 and 60 years service lives (Modahl et al., 2013). Also, Aktas and Bilec (2012) assessed the uncertainties related to building RSP for the US. Their results show firstly the increasing 
importance of renovation in the building life cycle due to the increasing number of low energy buildings, and secondly they noticed the variation between the expected building RSP and the monitored one.

In this paper, since the goal is to assess the material sensitivity to modelling choices, the reference area is of low interest - the different construction materials are affected in exactly the same manner by a change in the reference area. For the building reference study period, however, this assumption is not valid as the different construction materials are influenced by the building RSP.

\section{Results}

The LCA results shown in this study are displayed for the Global Warming Potential (GWP) impact category. Calculations are done with CML v4.1 GWP 100 , according to IPCC's methodology, as implemented in KBOB datasets and in the IBU EPDs (until mid 2014). The choice to limit the results to one impact category is made for the sake of clarity as we are presenting a large number of modelling choice uncertainties. However, the consequences of this limitation are discussed in the last section of the paper.

\subsection{Sensitivity to databases and datasets}

The databases sensitivity assessment is carried out on a whole building LCA, based on a Cradle-toGrave system boundary, discrete MSL and RSP of 60 years.

\section{Building level}

Fig. 3 presents the GWP results for the four buildings assessed with the different databases at building level. The results show a similar trend i.e. the MFH02 has systematically more GWP impact than the others MFH01, MFHO3 and MFHO4 whatever the database used. Wood based building MFHO3 has slightly lower impact than concrete based buildings MFHO1 and MFH04. However, MFH02, which is made with a combination of wood and concrete, has by far the largest impacts. Consequently, it seems that the design quality has more influence on results than the type of material used. Figure 3 shows that КВОВ and Ecoinvent databases results are close, with differences ranging from 0.2 to $0.9 \mathrm{~kg} \mathrm{CO}$-eq $/ \mathrm{m}^{2} \mathrm{a}, \mathrm{KBOB}$ having less GWP impact. A systematic lower GWP impact is apparent in Fig.3 for the EPD datasets as compared to the Ecoinvent or the KBOB datasets, with approximately $20 \%$ differences. The displayed differences in the GWP results can be related to two aspects. First, data origin variability plays a significant role: EPDs are based on foreground data provided by a manufacturer or a group of manufacturers, which might imply in different amount of inputs for each material. For instance, $\mathrm{KBOB}$ and Ecoinvent concrete blocks are modelled with $12.6 \%$ of cement, while the concrete block EPD considers a $4 \%$ input of cement. Secondly, the databases' 
calculation methods also contribute to the shown differences, e.g. sawn timber, as modelled on Ecoinvent and $\mathrm{KBOB}$ databases, does not consider negative $\mathrm{CO}_{2}$ values associated to using wood waste instead of fossil fuels for drying purposes, while the EPD for the same material does. Further details associated to each material category are explored in the next section.

\section{Construction material level}

In order to explore the variability between the databases in more detail, we looked at the relative contribution of each material to buildings' total GWP and at the difference induced by changing databases. Since $\mathrm{KBOB}$ datasets already adopt Ecoinvent processes as background data, in this section the latter was not considered. Fig. 4 displays the variation of GWP results for the EPD datasets in comparison to the КВОВ datasets (set as the reference database) at the material scale. Depending on the type of material, strong differences can be observed. Results sensitivity to the choice of EPD datasets differs between the various construction materials: "Windows \& Doors", "Insulation materials" and "Wood and wood products" are associated with strong sensitivity to the choice of datasets while "Cement based products" and the other materials show only minor sensitivity. It can also be noted that most of the building materials in the EPD database have a lower GWP than those in the KBOB datasets. Furthermore, the variation between the GWP results of the overall buildings for EPDs and KBOB datasets is driven by only a small number of construction materials. Typically, windows and insulation materials represent a significant contribution to the total impact (>10\%) and display a strong difference between datasets (>20\%).

\subsection{Sensitivity to the system boundaries}

For the evaluation of the system boundary sensitivities, the four buildings were modelled based on EPD datasets, in order to take advantage of the EPD modularity. Each material has a different material service life based on CSTB database (Hoxha et al., 2014) but the RSP for buildings is set at 60 years.

\section{Building level}

The GWP results for the four buildings with different system boundaries are shown in Fig. 5 . The following correlations between the buildings' construction type and their variability for different system boundaries can be observed: MFHO1 and MFHO4 (massive constructions) present similar magnitude of emissions for the different system boundaries; MFHO2 and MFHO3 (light and medium weight construction) on the other hand display strong variability in the results due to the high share of "Wood and wood products" in these two buildings and the chosen methodology used in the EPDs. The wood EPDs considered in this paper all accounted for biogenic carbon as negative $\mathrm{CO}_{2}$ values 
from phases A1-A3 (Cradle-to-Gate), but also considered $\mathrm{CO}_{2}$ emissions (positive values) from wood crushing and sorting in the disposal phase (Module C), and from wood incineration in the EoL phase (Module D). Also, while calculating Module $\mathrm{D}$, some declarations considered the avoided $\mathrm{CO}_{2}$ emissions associated to substituting fossil fuel based energy with energy from wood combustion. These differences between each module's assessment of $\mathrm{CO}_{2}$ emissions within the considered EPDs contributed to significantly increase results sensitivity to system boundaries for MFHO2 and MFHO3. The handling of wood products in LCA, and especially in the context of system boundary choice, is a controversially discussed topic in the LCA field: as discussed above, depending on the implementation, biomass products can reveal negative $\mathrm{CO}_{2}$ emissions (absorption) under the Cradleto-Gate system boundaries (as shown in Figure 5 for the MFH03 building), which, at the building level, may lead to low or negative emissions for Cradle-to-Gate building LCA. Further details are explained in the next section.

\section{Construction material level}

Figure 6 shows the Cradle-to-Cradle system boundary influence on the building LCA results through the evaluation of EN 15804 module D at the material scale. To recall, it refers to a "recycling content approach" for the EoL modelling.

Module D results vary among the different construction materials: for "Wood and wood products" it is preferential; "Windows and doors" benefit in a measured way; "Plaster", "Masonry" and "Cement based products" take none or negligible advantage of this module. The benefits magnitude from module D for "Wood and wood products" make those construction materials strongly sensitive to a change from a "Cut-Off" to an "Avoided burden" EoL modelling approach, even with a relative low environmental impacts contribution at the building level.

\subsection{Sensitivity to replacement scenarios and building reference study period}

This section combines the results of replacement scenario uncertainties and the buildings' RSP analysis. The building LCA was conducted applying Cradle-to-Grave system boundary. In order to maintain uniformity throughout databases choices, since EPDs were exclusively analyzed in the previous section, this specific analysis used KBOB datasets.

\section{Building level}

Figure 7 illustrates the buildings' environmental performance and the associated uncertainties for the replacement phase for the four building RSP (60 and 120 years). With uncertainties equaling approx. $10-20 \%$ of the buildings' overall GWP results, the sensitivity of building results to a variation in construction material service life can be considered as relevant. Even if the uncertainties are 
closely linked with replacement phase impacts magnitude, they are also influenced by the construction type: MFHO1 (massive construction) and MFHO3 (light weight construction) present approx. the same replacement phase impacts, but MFH01's replacement phase bears more uncertainty. This is probably due to the larger amount of insulation materials in MFHO1, which present significant uncertainty related to the replacement phase, as shown in Figure 8 and in Figure 9c.

Concerning buildings sensitivity to RSP, the four buildings indicate the same trend: an improvement in environmental performance for the longer RSP - as could be anticipated. Also, a shift in the life phases importance occurs when the RSP is extended: The material related impacts of the replacement phase increase while the impacts of the initial construction - associated to materials' cradle-to-gate impacts - and disposal phase decrease.

\section{Construction material level}

Figure 8 compares the buildings' LCA results for the RSP of 60 and 120 years at the material scale. One can see the correlation between the previous statements (impact increase for the replacement phase; decrease for the construction and disposal phases). The impacts results for cement based products and masonry decrease approx. by half, whereas the other materials (mainly those which require replacement) remain constant in terms of impacts, the decrease of impacts due to the RSP being compensated by the higher replacement rates. At the building level, this leads to impact reduction in the initial construction phase.

\section{Synthesis and Discussion}

We assumed that a construction material is sensitive if its contribution reaches at least $10 \%$ and if it is associated with a variability of more than $20 \%$ in regard to a reference scenario (or relative uncertainty). In that way, two categories of materials can be defined: the construction materials which are highly sensitive to modeling choices and the ones which are nearly insensitive.

As a synthesis of the previous results, Figure 9 presents in a schematic manner the relative sensitivity of each construction material to a) Databases and datasets, b) System boundary, c) Construction products service lives and d) Building RSP.

Results show, on the one hand, that "Wood and wood products", "Insulation materials" and "Windows and doors" display a strong sensitivity to most modelling choices: within database, system boundaries and materials' service life choices, parts (or all) of those materials' categories present high sensitivity either in impact share or results' variability. On the other hand, "Cement based products" and "Masonry" are mainly affected by the building RSP. Finally, for the other materials, such as sealings and coverings, changes in the four assessed modelling choices do not affect the 
overall LCA results of the buildings in a significant way as their contribution to the total building impact is not significant.

Concerning the databases, the material sensitivity originates from the background data. Most EPDs utilized in this study have been calculated with $\mathrm{GaBi}$ data, while KBOB background data originates essentially from Ecoinvent data. In addition, some differences between EPDs and KBOB can be due to the use of product-specific foreground data: while КВOB aims to be nationally applicable, which requires average inputs, EPDs depend on data provided by manufacturers to provide reliable information on a specific product under assessment. Sensitivity results found due to database variation are very much in line with the findings from Modahl et al (2013), which showed that using two datasets with different degrees of specificity implies in substantial differences, which become greater the more distinctive the assessed material is.

For module $\mathrm{D}$, the material sensitivity is strongly connected to biomass construction materials (e.g. wood) use, as these materials' End-of-Life impacts are crucial for the greenhouse gas emissions as well as for the energy balance. In the case of "Windows and doors", wood is also one of the main contributors to these products' LCA results, so that the share of wood influences their sensitivity to module D. The variability found for wood products EoL was mainly related to the avoided burnt fossil fuels due to wood incineration for energy generation purposes, as discussed in section 3.2. The sensitivity significance is corroborated by Röder et al (2014), who found that, depending on the evaluation method or supply chain considered, wood pellets burning $\mathrm{CO}_{2 \text {-eq }}$ emissions can range from 132 to 1330 g.kWh ${ }^{-1}$. The fact that these EPDs assess wood waste pellets might increase the variability even more (Rabaçal et al., 2013). At last, Sandin et al (2014) assessed the EoL modelling assumption influence on two roof construction elements, wooden beams and steel frame, and concluded that the choice of EoL modelling methodology had significant influence on their studied impact categories

The uncertainties due to material replacement are linked to the materials' service life. It can be seen that the construction materials classified as "highly sensitive" have a shorter service life than the building RSP, which, of course, allows for higher possibility of variation. Furthermore, it is notable that those materials are also not influenced by the buildings long life spans, as opposed to all structural materials like "Cement based products" and "Masonry" (excluded structural wood elements). As shown in this study, the uncertainty on service lives may lead to strong variation in building LCAs. This was also discussed and proved by Rauf and Crawford (2015). A clear definition of buildings' and materials' service lives should be an important upcoming topic for buildings LCAs, especially as the evaluation of embodied energy and emissions is anticipated to become a general standard in the sustainable construction field in the near future. Until now, however, only few studies assess this topic. 
In this study, the results were presented for the sake of clarity only for the GWP impact category. Although a usual LCA study covers more than one impact category, we expect that this study's uncertainty trends will be similar for most other environmental impact categories currently used for EPDs in the EN 15804 standard. This will be particularly true for impact categories linked to nonrenewable energy consumption or related emissions (e.g. acidification, photochemical ozone formation, abiotic depletion potential etc.). Actually recent work showed a high correlation between impact categories used in EPDs (Lasvaux et al., 2015) and as long as no additional indicators will be added as suggested by the recent CEN TC350, the GWP will be a reasonable proxy for other impact categories. Even if some shifts in the different material contributions to the buildings' environmental performance may occur for these indicators, the variability will presumably display the same magnitude or trend as shown in the GWP 100a results.

However, in the case of parameters describing waste flows in EN 15804, different trends are expected as for instance in the case of concrete products. While the GWP impact of this construction material is mostly driven by the cement contribution, in the case of e.g. the non-hazardous waste flows, most of the contribution is driven by the aggregates, which have a high reuse and recycling potential that strongly affects this material's module $D$ results. Therefore, attention should be paid when extrapolating the sensitivity of construction materials to other LCA indicators even though most of them should display the same trends.

\section{Conclusion}

In this paper, we have shown that uncertainties linked with building materials have significant consequences on the final LCA result at the building scale. We have also been able to highlight the fact that not all materials react similarly to the analyzed uncertainties and do not have the same impact on the overall results.

In particular, we have been able to identify the critical influence that insulation materials as well as doors and windows have on the uncertainties related to the functional unit, database and replacement scenario choices. This is due to their non-negligible contribution to the overall impact and to the fact that these aspects strongly influence the environmental impact of these building materials. A harmonization between the various databases is urgently needed, in order to decide how to define materials reference service life and to clearly highlight the strong consequences of incorporating the module D from the EPDs in the building's LCA calculation.

In Europe, the ECO Platform stands out as a sound source for harmonization purposes. The platform consists of an International Non-Profit Association established by the European EPD Program Operators, which allows for verification procedures and certification of verifiers, providing a list of criteria to check for harmonization assurance. Also, the European Commission (EC) developed, in 
addition to the CEN/TC350 framework and the EN 15804, the Product and Organization Environmental Footprint (PEF and OEF) methods. The PEF method aims to furthermore guarantee consistent and reproducible results when assessing the environmental performance of a product, good or service throughout its life cycle. We then expect that harmonization could soon be reached at the European level, but more scientific studies (as the one herein presented) that look into the influence of using different databases are needed to better assess this issue worldwide.

Furthermore, this study shows that cement and concrete products as well as masonry products are mainly sensitive to the choice of the building Reference Study Period (RSP). This means that the RSP choice strongly controls the overall relative contribution of these products and influences the further actions that might be taken to reduce the environmental impact associated with buildings. If a long RSP is chosen, the focus for buildings impact assessment lies on insulation materials as well as doors and windows. If a reduced RSP is chosen, concrete and masonry materials are the main priority to reduce buildings environmental impact.

\section{Acknowledgements}

The authors are grateful to the CSTB for providing the detailed database on effective service lives of building products. The association of the Swiss cement industry, Cemsuisse, is acknowledged for the financial support they have provided to perform this study, as well as for the constructive comments and remarks they have made all along the project. The Authors also thank the SNF IZKOZ2_154373 for providing financial support for the international short visit of Alexander Passer to collaborate within the project.

\section{Appendix}

\begin{tabular}{|l|l|}
\hline Cement based products & $\begin{array}{l}\text { Adhesive mortar, cement cast plaster floor, cement mortar, poor } \\
\text { concrete, concrete normal, foundation plates, reinforcing steel. }\end{array}$ \\
\hline Masonry & Concrete bricks, bricks, sand lime bricks, cement mortar(for masonry) \\
\hline Insulation materials & $\begin{array}{l}\text { Glass wool mat, Foam glass, polystyrene foam slab, polystyrene extruded, } \\
\text { polyurethane rigid foam, rock wool, cellulose fiber }\end{array}$ \\
\hline Wood and wood products & $\begin{array}{l}\text { Sawn timber softwood raw and planed, three layered laminated board, } \\
\text { medium density fiberboard, oriented strand board, fiberboard soft, glues } \\
\text { laminated wood, fiberboard hard }\end{array}$ \\
\hline Plaster and gypsum products & Base plaster, cover coat, stucco gypsum plaster and fiber board \\
\hline Sealings & $\begin{array}{l}\text { Fleece polyethylene, polypropylene granulate synthetic rubber, bitumen } \\
\text { sealing }\end{array}$ \\
\hline
\end{tabular}




\begin{tabular}{|l|l|} 
Mineral covering & $\begin{array}{l}\text { Limestone sand, natural stone plate, expended perlite, sanitary ceramics, } \\
\text { sand, gravel, fiber cement facing tiles and roof slates }\end{array}$ \\
\hline Windows and doors & Glazing double and triple, wood aluminum door, wood aluminum window \\
\hline
\end{tabular}

\section{References}

Aktas, C.B., Bilec ,M.M., 2012. Impact of lifetime on Us residential building LCA results. Int. J. Life Cycle Assess. 17, 337-349.

Anand, C., Amor, B., 2017. Recent developments, future challenges and new research directions in LCA of buildings: A critical review. Renew. Sustain. Energ. Rev. 67, 408-416

Blengini, G.A., Di Carlo, T. 2010a. Energy-saving policies and low-energy residential buildings: an LCA case study to support decision makers in Piedmont (Italy). Int. J. Life Cycle Assess. 15, 652-665.

Blengini, G.A., Di Carlo, T. 2010b. The changing role of life cycle phases, subsystems and materials in the LCA of Low energy buildings. Energ. Build. 42, 869-880.

Braungart, M., McDonough, W., Bollinger, A., 2007. Cradle-to-Cradle design: creating healthy emissions - a strategy for eco-effective product and system design, J. Clean. Prod. 115, 1337-1348.

Environdec, 2016. International EPD platform. www.environdec.com/ (accessed, 08.04.2017)

EN 15804:2012: Sustainabilitys of construction works - Environmental product declarations - Core rules for the product category of construction products, Brussels (Belgium). European committee for Standardization, 2012.

EN 15978:2011: Sustainability of construction works - Assessment of environmental performance of buildings - Calculation method, Brussels (Belgium). European Committe for Standardization, 2011.

Frischknecht, R., 2010. LCl modelling approaches applied on recycling of materials in view of environmental sustainability, risk perception and eco-efficency. Int. J. Life Cycle Assess. 15, 666-671.

Frischknecht, R., Jungbluth, N., 2007. Overview and Methodology. ecoinvent report No. 1, Dübendorf: Swiss Centre for Life Cycle Inventories.

Frischknecht, R., Wyss, F., Knöpfel, S. B., Stolz, P. 2015. Life cycle assessment in the building sector: analytical tools, environmental information and labels. Int. J. Life Cycle Assess. 20, 421-425 
Gomes, F., Brière, R., Feraille, A., Habert, G., Lasvaux, S., Tessier, C., 2013. Adaptation of environmental data to national and sectorial context: application for reinforcing steel sold on the French market. Int. J. Life Cycle Assess. 118, 926-938.

Heijungs, R., 1996. Identification of key issues for further investigation in improving the reliability of life-cycle assessments. J. Clean. Prod. 4, 159-166.

Hong, J., Shen, G.Q., Peng, Y., Feng, Y., Mao, C., 2016. Uncertainty analysis for measuring greenhouse gas emissions in the building construction phase: a case study in China. J. Clean. Prod. 129, 183-195.

Hoxha, E., Habert, G., Chevalier, J., Bazzana, M., Le Roy, R., 2014. Method to analyse the contribution of material's sensitivity in buildings' environmental impact. J. Clean. Prod. 66, 154-64.

Huijbregts, M.A.J., 1998. Application of Uncertainty and Varaiability in LCA. Int. J. Life Cycle Assess. 3, 273-280.

IBU, 2016. Institut Bauen und Umwelt e.V., Published EPDs. www.ibu-epd.com/en/epdprogram/published-epds/ (accessed 08.04.2017).

ISO, 2006. ISO 14025, Environmental labels and declarations - Type III environmental declarations Principles and procedures, International Organization for Standardization.

ISO, 2006. ISO 14040, Environmental management -- Life cycle assessment -- Principles and framework. International Standard Organisation.

ISO, 2014. ISO 13315, Environmental management for concrete and concrete structures. International Standard Organisation.

John, V., 2012. Derivation of reliable simplification strategies for the comparative LCA of Individual and Typical newly built Swiss Apartement buildings, Zurich. Diss., Eidgenössische Technische Hochschule ETH Zürich, Switzerland. Nr. 20608.

KBOB, 2009. Koordinationskonferenz der Bau- und Liegenschaftsorgane der öffentlichen Bauherren (KBOB), Empfehlung Ökobilanzdaten im Baubereich 2009/1, www.kbob.admin.ch/kbob/de/home/publikationen/nachhaltigesbauen/oekobilanzdaten_baubereich.html. (accessed 08.04.2017).

Lasvaux, S., Habert, G., Peuportier, B., Chevalier, J., 2015. Comparison of generic and product-specific Life Cycle Assessment databases: application to construction materials used in building LCA studies. Int. J. Life Cycle Assess. 20, 1473-1490. 
Lloyd, S.M., Ries, R., 2007. Characterizing, Propagating, and Analyzing Uncertainty in Life-Cycle Assessment. J. Ind. Ecol. 11, 161-179.

Modahl, I. S., Askham, C., Lyng, K.-A., Skjerve-Nielssen, C., Nereng, G., 2013. Comparison of two versions of an EPD, using generic and specific data for the foreground system, and some methodological implications. Int. J. Life Cycle Assess. 18, 241-251.

Murtha, J., 2000. Decisions Involving Uncertainty: an @RISK Tutorial for the Petroleum Industry, second ed., New York.

Noshadravan, A., Wildnauer, M., Gregory, J., Kirchain, R., 2013. Comparative pavement life cycle assessment with parameter uncertainty. Transp. Res. Part D. 25, 131-138.

Passer, A., Lasvaux, S., Allacker, K., De Lathauwer, D., Spirinckx, C., Wittstock, B., Wallbaum, H., 2015. Environmental product declarations entering the building sector: critical reflections based on 5 to 10 years experience in different European countries. Int. J. Life Cycle Assess. 20, 1199-1212.

Peereboom, E. C., Kleijn, R., Lemkowitz, S., Lundie, S., 2008. Influence of Inventory Data Sets on LifeCycle Assessment Results: A Case Study on PVC. J. Ind. Ecol. 2, 109-130.

Rabaçal, M., Fernandes, U., Costa, M., 2013. Combustion and emission characteristics of a domestic boiler fired with pellets of pine, industrial wood wastes and peach stones. Renew. Energ. 51, 220226.

Rauf, A., Crawford, R.H., 2015. Building service life and its effect on the life cycle embodied energy of buildings. Energy. 79, 140-148.

Reap, J., Roman, F., Duncan, S., Bras, B., 2008. A survey of unresolved problems in life cycle assessment Part 1: goal and scope and inventory analysis. Int. J. Life Cycle Assess. 113, 290-300.

Röder, M., Whittaker, C., Thornley, P., 2014. How certain are greenhouse gas reductions from bioenergy? Life cycle assessment and uncertainty analysis of wood pellet-to-electricity supply chains from forest residues. Biomass Bioenerg. 79, 50-63.

Sandin, G., 2014. Life cycle assessment of construction materials: the influence of assumptions in end-of-life modelling. Int. J. Life Cycle Assess. 119, 723-731.

Sartori, I., Hestnes, A.G., 2007. Energy use in the life cycle of conventional and low energy buildings: a review article. Energ. Build. 39, 249-257.

SIA, 2010. Merkblatt SIA 2032 Graue Energie von Gebäuden, Zurich: Swiss society of engineers and architects, SIA. 
Silvestre, J., de Brito, J., Pinheiro, M., 2014. Environmental impacts and benefits of the end-of-life of building materials - calculation rules, results and contribution to a "cradle-to-cradle life cycle". J. Clean. Prod. 66, 37-45.

Takano, A., Winter, S., Hughes, M., Linkosalmi, L., 2014. Comparison of life cycle assessment databases: A case study on building assessment. Build. Environ. 79, 20-30.

Tillman, A.-M., Ekvall, T., Baumann, H., Rydberg, T., 1993. Choice of system boundaries in life cycle assessment, J. Clean. Prod. 2, 21-29.

UNSTAT, 2010. Greenhouse Gas Emissions by Sector (Absolute Values).,» United Nation Statistical Division, New York.

Wang, E., Shen, Z., Neal, J., Shi, J., Berryman, C., Schwer, A., 2012. An AHP-weighted aggregated data quality indicator (AWADQI) approach for estimating embodied energy of building materials. Int. J. Life Cycle Assess. 17, 764-773.

\section{Table Caption}

Table $1-$ General information of the four buildings

\section{Figure caption}

Figure 1 Main construction material composition for the four buildings - Masses of materials per square meter of energy reference area for a) Reinforced concrete, b) Wood, c) Masonry and d)

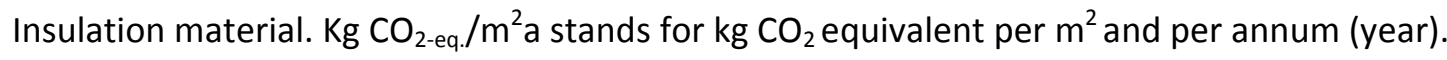

Figure 2 - System boundaries as implemented in EN 15978

Figure 3: Comparison of databases at the building level - Building LCA results modelled with the three databases and datasets: Ecoinvent, $\mathrm{KBOB}$ datasets and EPDs. $\mathrm{Kg} \mathrm{CO}_{2 \text {-eq. }} / \mathrm{m}^{2}$ a stands for $\mathrm{kg} \mathrm{CO}_{2}$ equivalent per $\mathrm{m}^{2}$ and per annum (year).

Figure 4: Comparison of databases at the material scale - On the horizontal axis: the material contribution to the buildings' environmental impacts; on the vertical axis: the impact variation for EPDs (reference database KBOB).

Figure 5: Comparison of system boundaries at the building level - The environmental impact for the four buildings under different system boundaries. Impact category: $\mathrm{GWP}_{100} . \mathrm{Kg} \mathrm{CO}_{2 \text {-eq. }} / \mathrm{m}^{2} \mathrm{a}$ stands for $\mathrm{kg} \mathrm{CO}_{2}$ equivalent per $\mathrm{m}^{2}$ and per annum (year). 
Figure 6: Comparison of system boundaries at the material scale - On the horizontal axis: the material contribution to the buildings' environmental impacts; on the vertical axis: the impact due to the module $D$ (reference system boundary: Cradle-to-Grave).

Figure 7: Replacement phase uncertainties at the building level - Uncertainties of the replacement phase for different building reference study periods (60 and 120 years). Error bars represent $2 \sigma$. $\mathrm{Kg} \mathrm{CO}$-eq. $/ \mathrm{m}^{2}$ a stands for $\mathrm{kg} \mathrm{CO}_{2}$ equivalent per $\mathrm{m}^{2}$ and per annum (year).

Figure 8: Replacement phase uncertainties at the material scale - Uncertainties of the replacement phase for different building reference study periods evaluated for the materials (60 and 120 years). Error bars represent $2 \sigma . \mathrm{Kg} \mathrm{CO}$-eq. $/ \mathrm{m}^{2}$ a stands for $\mathrm{kg} \mathrm{CO}_{2}$ equivalent per $\mathrm{m}^{2}$ and per annum (year).

Figure 9: Synthesis of results - Schematic sensitivity of the materials to modelling choices concerning: a) databases and datasets, b) System boundary, c) Material Service Lifes and d) Building RSP. The highlighted area refers to a strong sensitivity zone. 


\begin{tabular}{lcccc}
\hline General information & MFH01 & MFH02 & MFH03 & MFH04 \\
\hline Construction type & Massive & Medium weight & Light weight & Massive \\
Energy reference area $\left[\mathrm{m}^{2}\right]$ & 12,430 & 350 & 374 & 622 \\
Net floor area $\left[\mathrm{m}^{2}\right]$ & 16,746 & 886 & 517 & 868 \\
Swiss energy standard & Minergie & Minergie-Eco & Minergie-P & SIA 380/1 \\
Annual Heating demand $\left[\mathrm{kWh} / \mathrm{m}^{2}\right]$ & 56 & 44 & 30 & 73 \\
Number of accomodation units & 111 & 2 & 3 & 4 \\
Number of floors & 5 & 3 & 3 & 2 \\
Existence of a basement & Yes & Yes & No & Yes \\
\hline
\end{tabular}



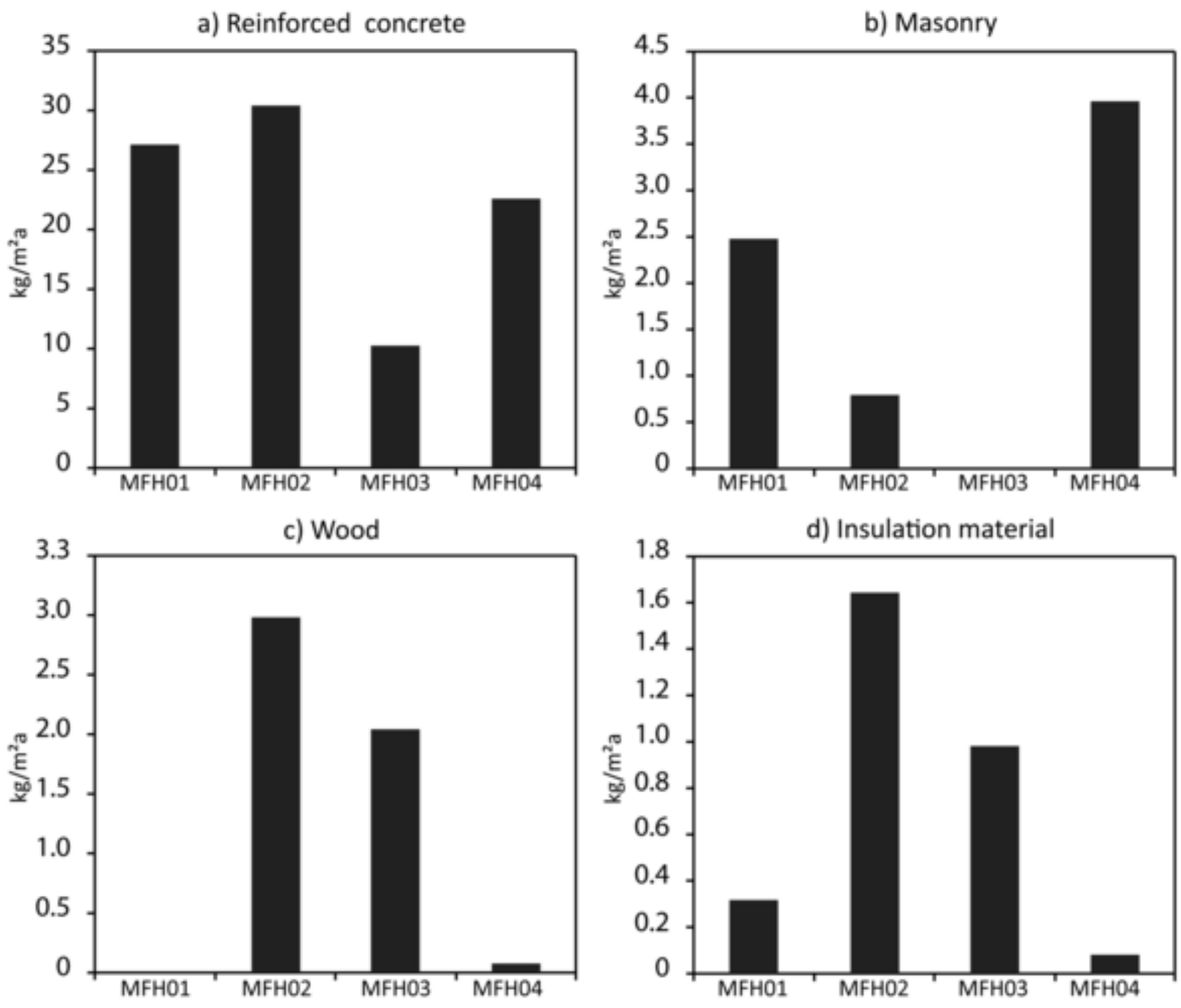


\begin{tabular}{|c|c|c|c|c|}
\hline \multicolumn{5}{|c|}{ Building assessment information } \\
\hline \multicolumn{3}{|c|}{ Building Life Cycle information } & \multirow{2}{*}{ ': } & \multirow{2}{*}{$\begin{array}{c}\begin{array}{c}\text { Suppl. information } \\
\text { beyond life cycle }\end{array} \\
\text { Beyond Life Cylce }\end{array}$} \\
\hline Product stage & Use & End-of-Life (EoL) & & \\
\hline A1 Raw mat. extraction & \multirow[t]{3}{*}{ B4 Replacement } & $\begin{array}{c}\mathrm{C} 1 \\
\begin{array}{c}\text { De-construction } \\
\text { / Demolition }\end{array}\end{array}$ & $\mid$ & \multirow{3}{*}{$\begin{array}{c}\text { Reuse, } \\
\text { Recovery } \\
\& \\
\text { Recycling potential }\end{array}$} \\
\hline A2 Transport & & C3 Waste processing & 1 & \\
\hline A3 Manufacturing & & C4 Disposal & | 1 & \\
\hline Cradle-to-Gate & \multicolumn{4}{|c|}{ Cradle-to-Grave } \\
\hline
\end{tabular}



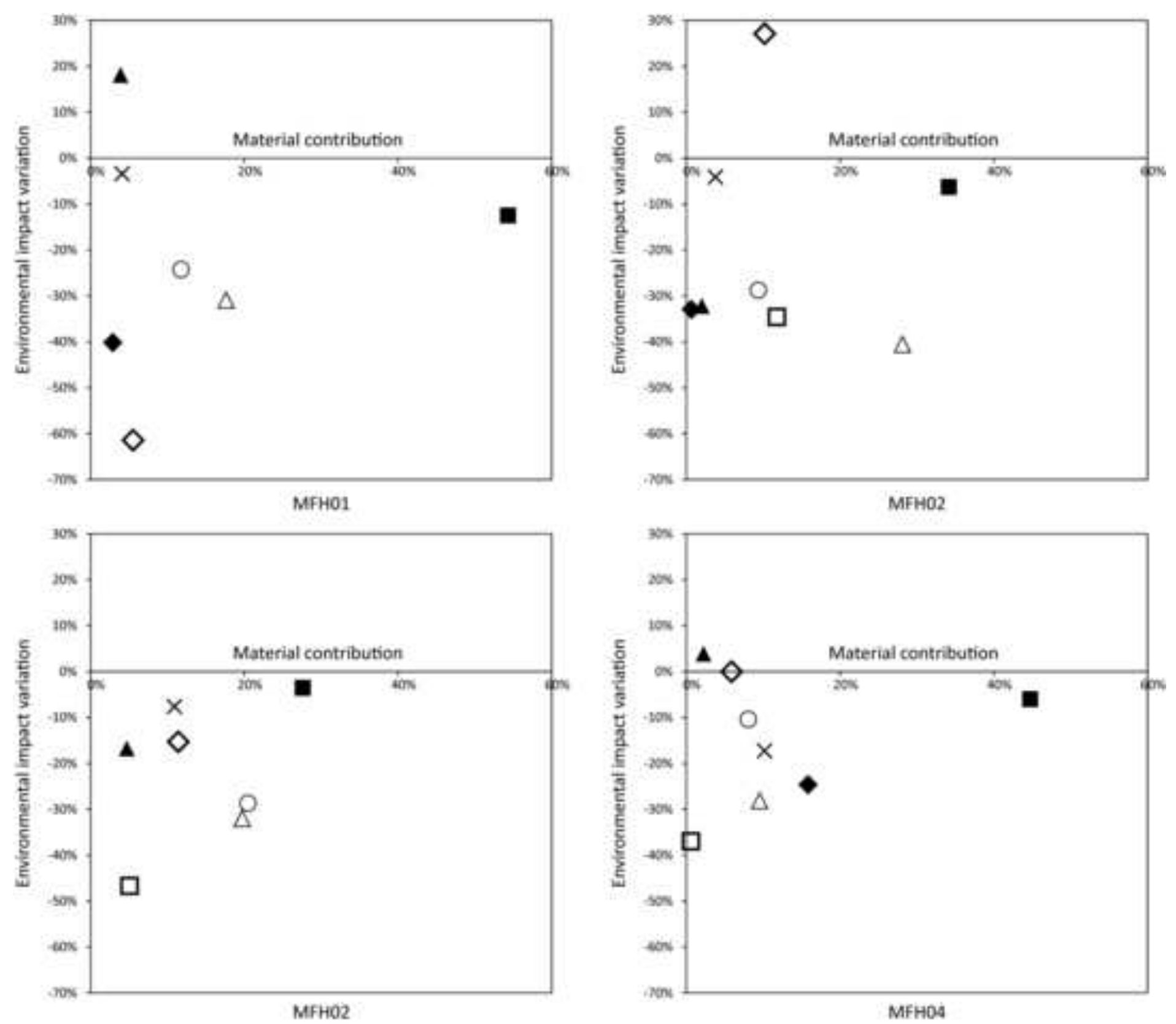

\begin{tabular}{|lllllll|}
\hline - Cement based products & $\circ$ & Windows and doors & $\diamond$ & Mineral covering & $\times$ & Sealings \\
- Masonry & $\square$ & $\begin{array}{l}\text { Wood and wood } \\
\text { products }\end{array}$ & $\Delta$ & Insulation materials & $\Delta$ & $\begin{array}{l}\text { Plaster and gypsum } \\
\text { products }\end{array}$ \\
\hline
\end{tabular}




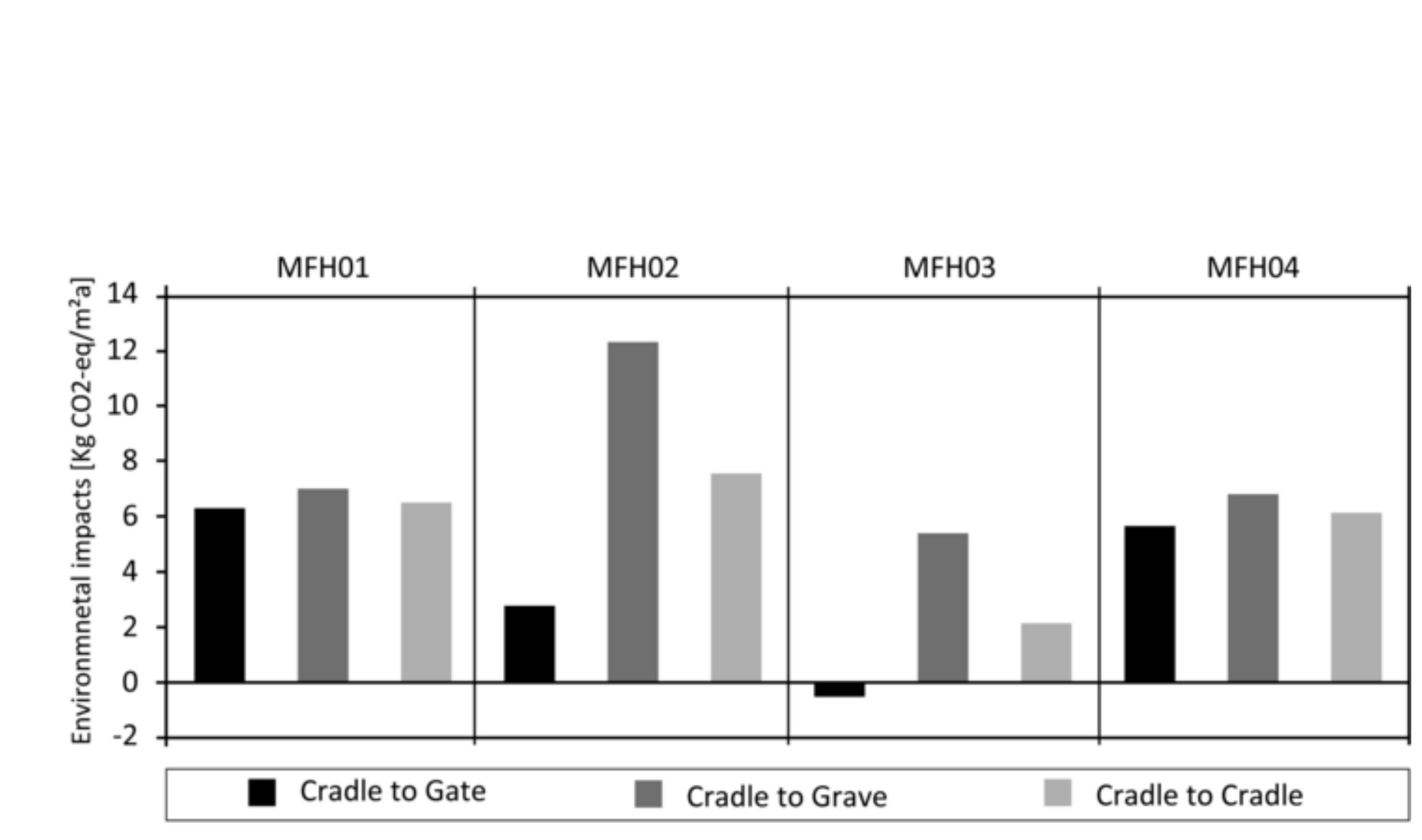



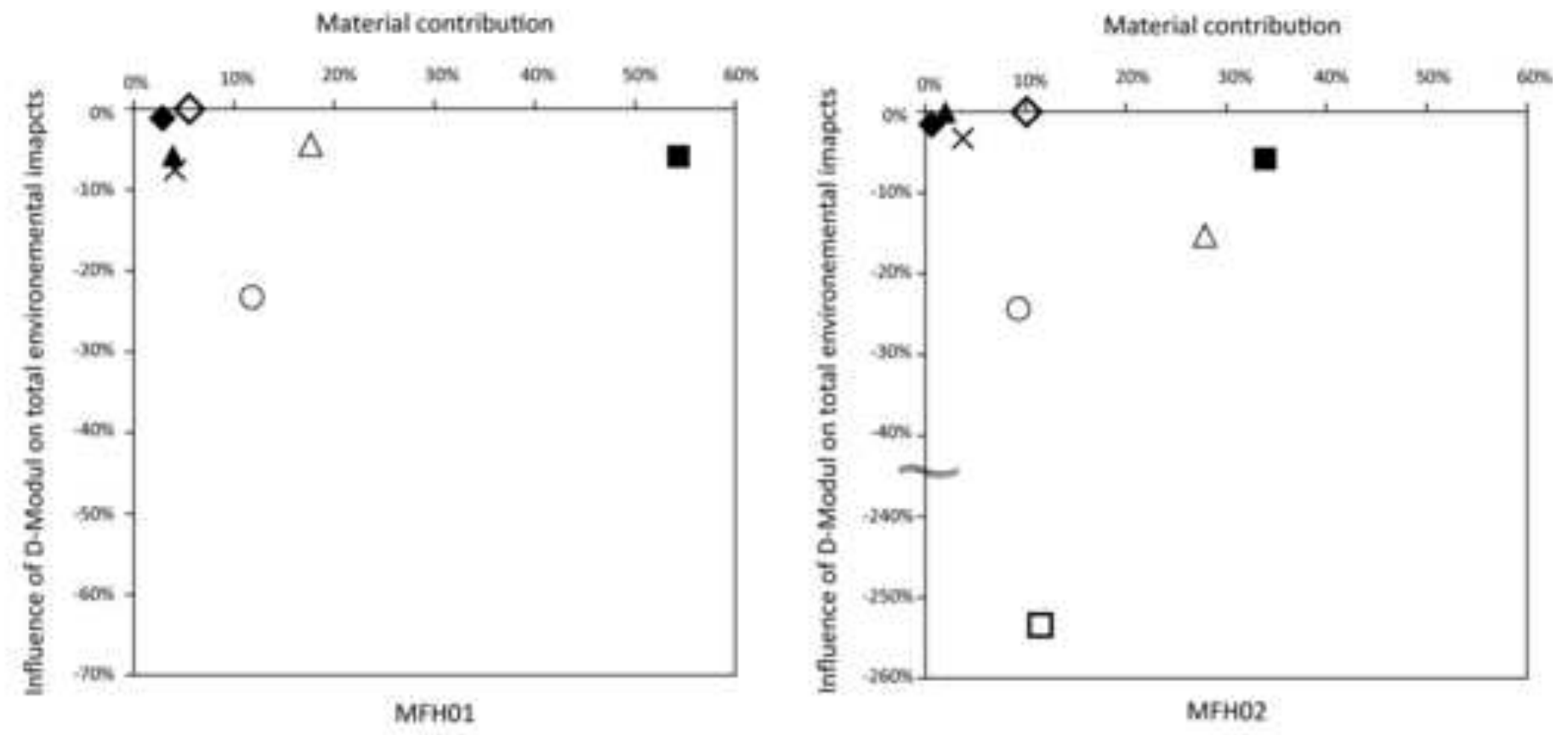

Material contribution
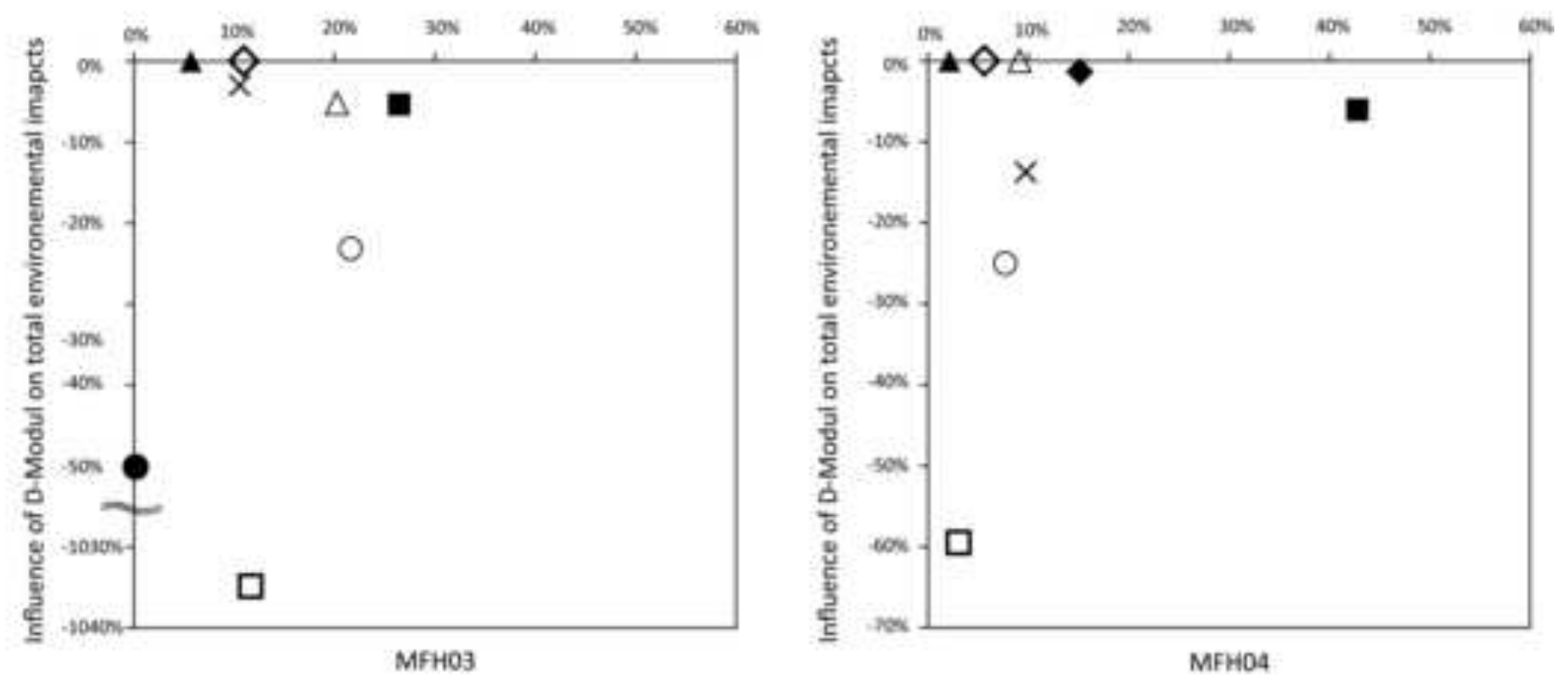

\begin{tabular}{|c|c|c|c|c|c|c|}
\hline Cement based products & O & Windows and doors & $\theta$ & Mineral covering & $x$ & Sealings \\
\hline Masonry & $\square$ & $\begin{array}{l}\text { Wood and wood } \\
\text { products }\end{array}$ & $\Delta$ & Insulation materials & $\Delta$ & $\begin{array}{l}\text { Plaster and gypsum } \\
\text { products }\end{array}$ \\
\hline
\end{tabular}




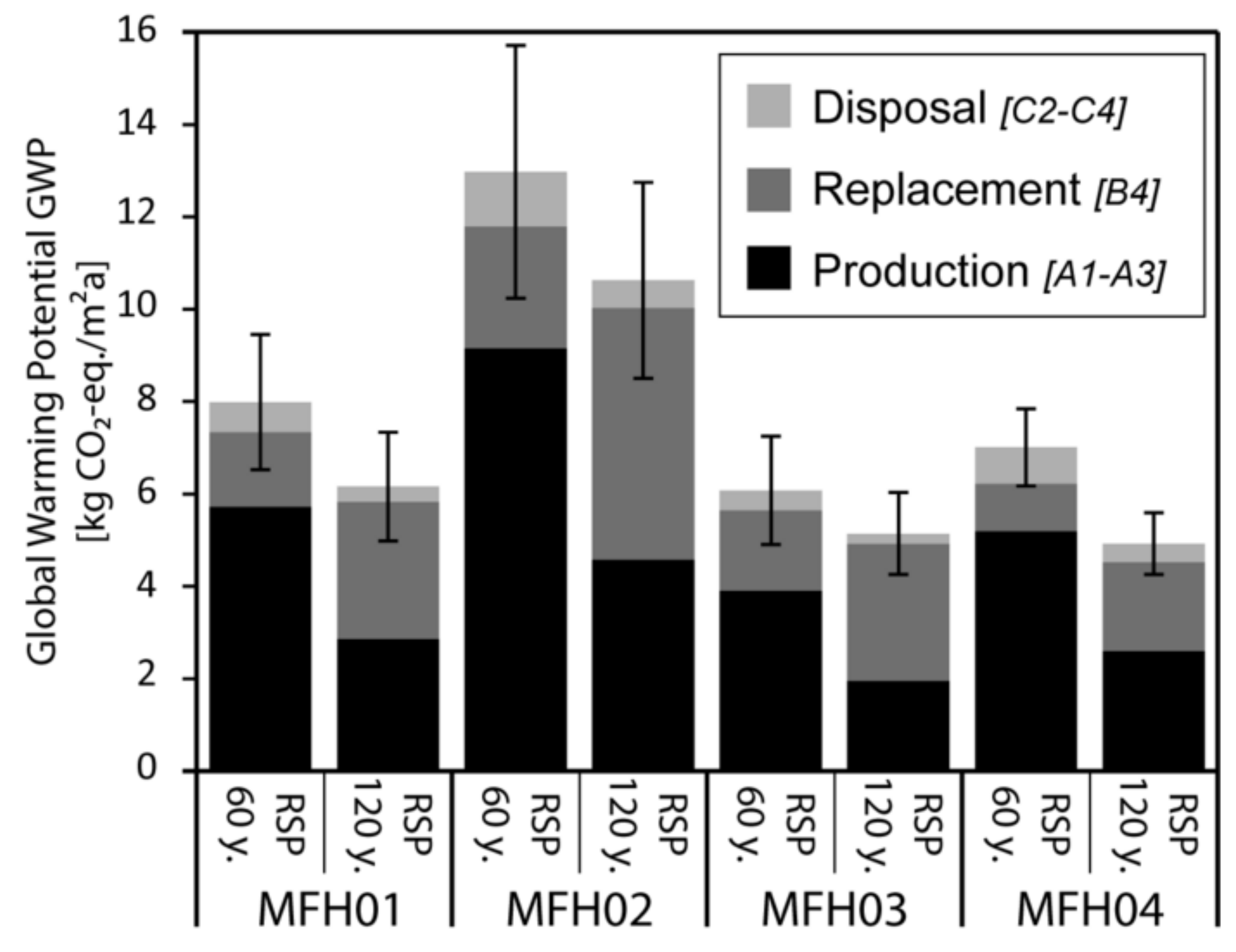


a) Building RSP of 60 years

Global Warming Potential GWP [ $\mathrm{kg} \mathrm{CO} \mathrm{CO}_{2}-\mathrm{eq} / \mathrm{m}^{2} \mathrm{a}$ ]

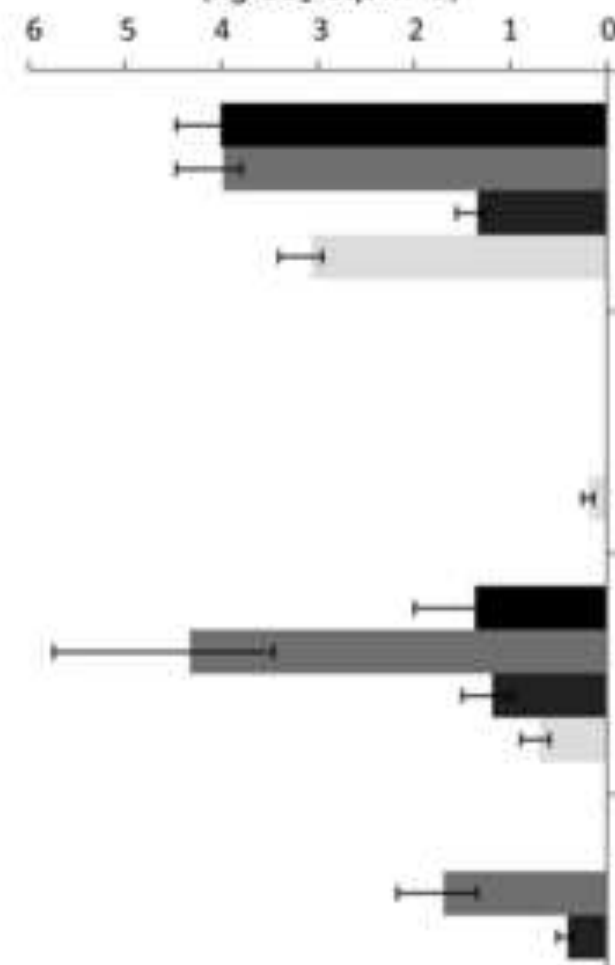

b) Building RSP of 120 years

Global Warming Potential GWP [kg $\mathrm{CO}_{r} \mathrm{eq} / \mathrm{m}^{2}$ a]

0

\section{Cement based} products

$\begin{array}{lllllll}0 & 1 & 2 & 3 & 4 & 5 & 6\end{array}$
steel
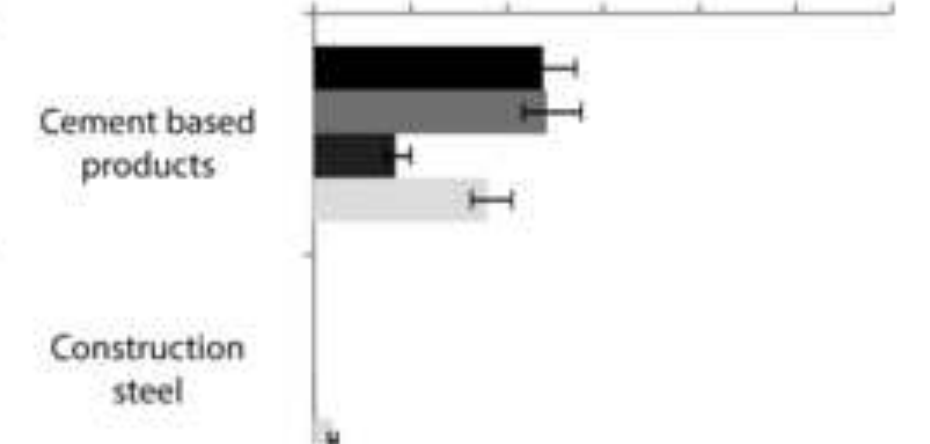

Wood and wood products

Insulation materials

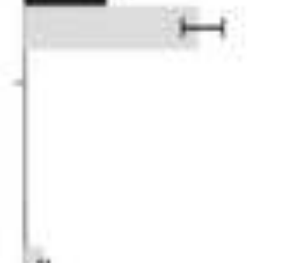

H
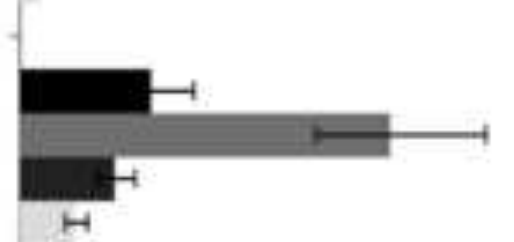

$H$

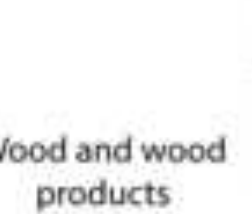

Plaster and gypsum products

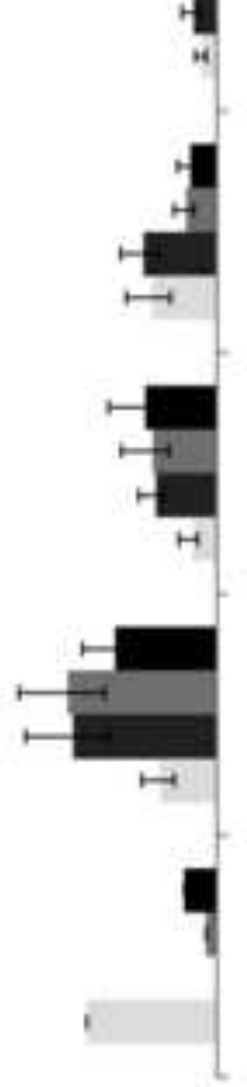

Mineral covering

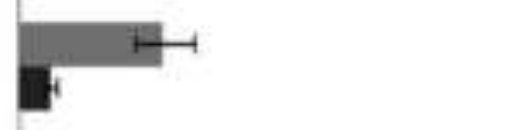

\section{Sealings}

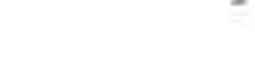

Windows and doors.
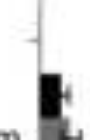

MFHOI

$\mathrm{MFHO2}$
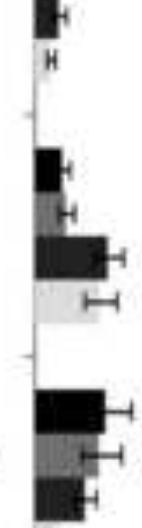

MFHO3

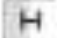

MFHO4

Masonry

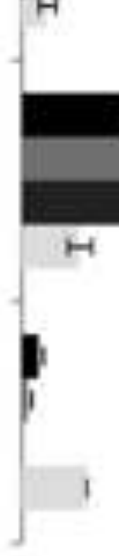


a) Databases and Datasets

Impacts share at the building level

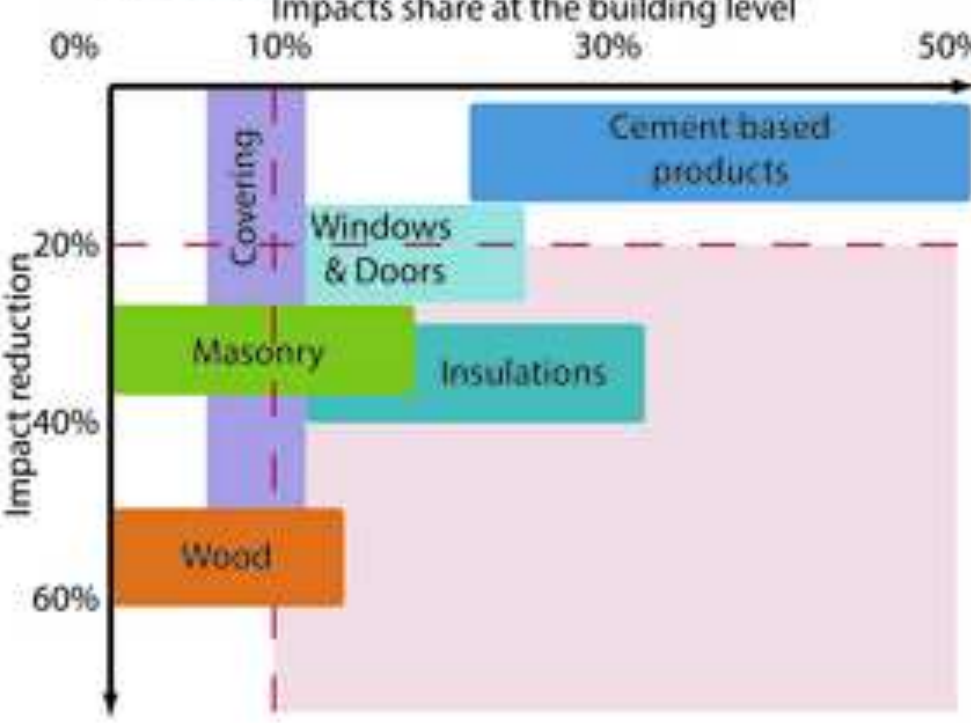

c) Material service lives

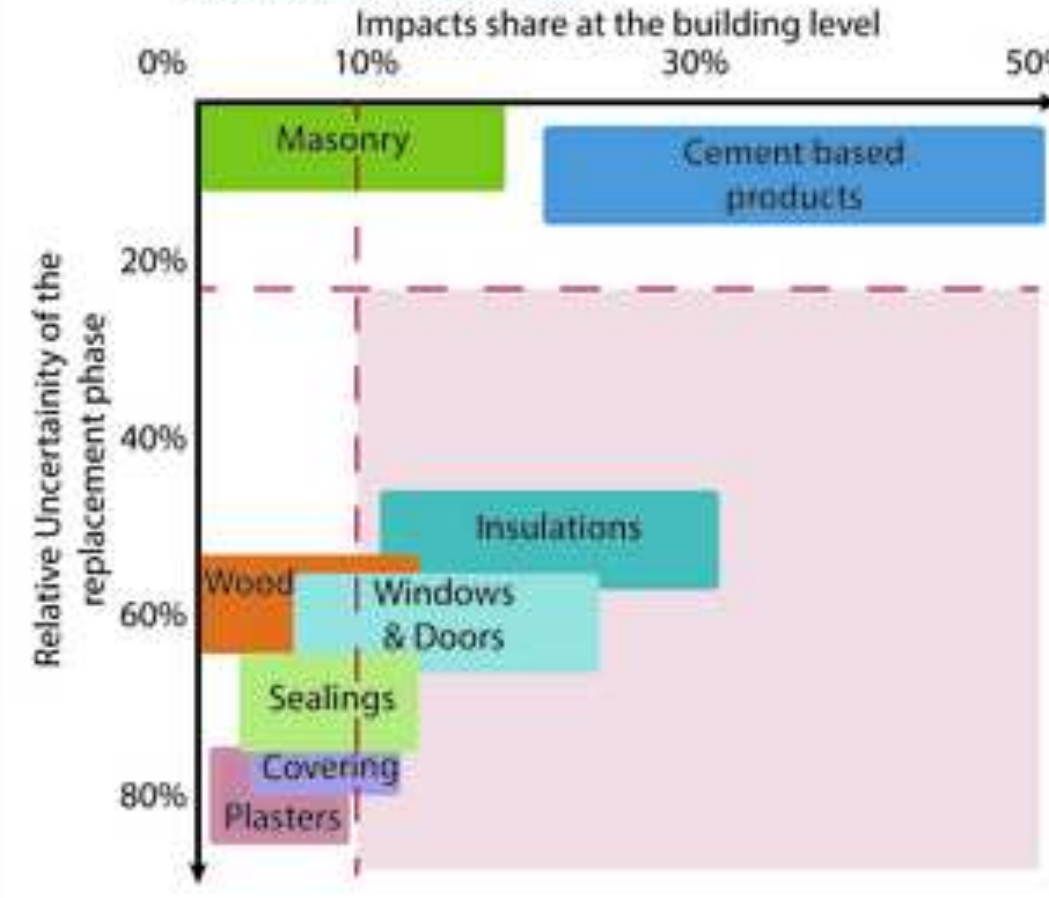

\section{b) System boundary}

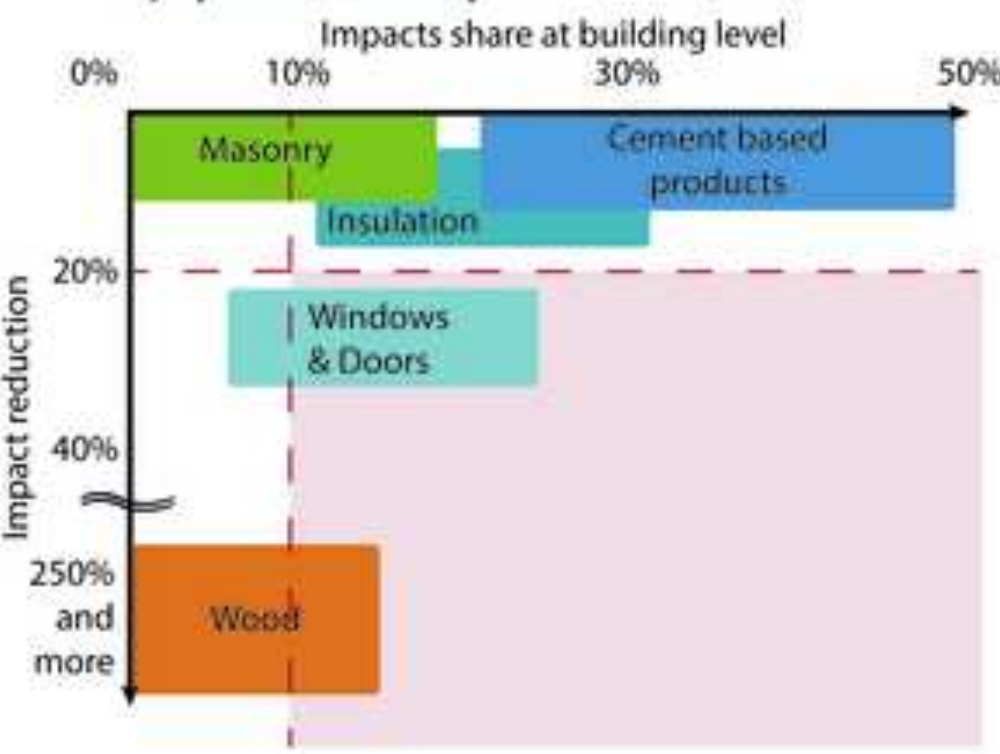

d) Building RSP

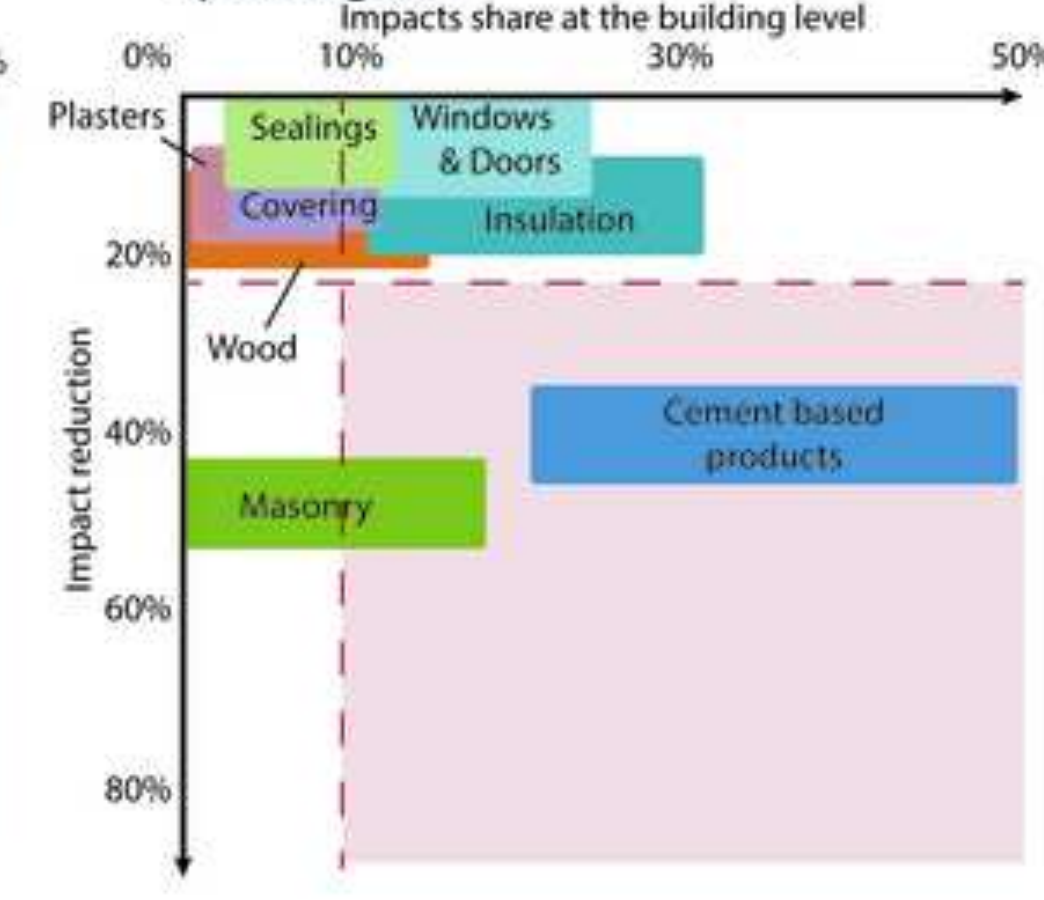

$50 \%$ 